\title{
Objects for peaceful disordering: Indigenous designs and practices of protest
}

\author{
Sheffield Hallam University \\ Sheffield \\ S11 8UZ \\ UK
}

\author{
Tom Fisher
}

\section{t.h.fisher@shu.ac.uk}

\begin{abstract}
What do a piece of plumbing pipe, some wire netting, some adhesive tape, two loops of nylon webbing and a carabiner have in common? Nothing, until they are assembled, in a design. In turn, the object these components comprise comes into being only with the presence of human beings. These are the components of a device known as a 'lock-on'; some sundry objects that you would find in a builders' merchant and some people's bodies - peace activists pursuing non-violent direct action. Peace activists use lock-ons to join themselves together by the arms to enhance the power of their passive resistance. This paper identifies a number of theoretical approaches to objects of this sort. It is intended to initiate a discussion of the lock-on as an example of an 'indigenous' design that has appeared without professional designers, evolving as part of the practice of peace protest.
\end{abstract}

As well as considering the way that the lock-on may have evolved, referring to Langrish's (2004) analysis of design in terms of Darwinian evolution, the paper refers to 'practice' in the sense found in the sociological study of culture, in the work of Bourdieu (1977) and others, summed up recently by Reckwitz (2002). Drawing as it does from a range of sources, including the social study of technology, 'practice theory' seems to have a good deal to offer a conception of design that seeks to influence the world positively beyond the point of sale. In common with other recent strands in design research such as the Participative Design that has grown out of the study of human computer interaction, practice theory acknowledges that our relationships to objects are socially important. Together with cultural knowledge and embodied skill objects form 'compounds' with people that evolve through time (Shove 2006).

This paper raises the possibility that the transforming power of designing may be enhanced if it is acknowledged that it is most powerful when it takes place in full articulation with practices. This principle is inscribed in contemporary 'user oriented' design process, but the lock-on is an extreme example of it, since no professional designers are involved in its production and its social purpose is not commercial but political. Politically engaged design is often directed at issues of sustainability and work with NGOs and these contexts for designing may be the closest in kind to that which has produced the lock-on.

A 'practice orientated' approach to design might be able to engage with the full relationship between things and the agents they imply, their bodies, their minds, the knowledge they have, the emotions they feel, the discourses they engage with. For this reason it seems to be a useful framework through which to understand an object like the lock on which has emerged out of an identifiable practice. The nature of this practice may also be inspiring in itself, as in this example, which works against weapons of mass destruction. The paper offers an initial analysis of the evolution and current use of the 'lock-on' in UK non violent direct action as an example of an indigenous design that is part of a practice and indicates the potential for further research that would seek more fully to understand the history and development of the lock-on to both test the applicability of practice theory and to seek insights into human/ object relationships in other contexts. 
"Nonviolent direct action seeks to create such a crisis and foster such a tension that a community which has constantly refused to negotiate is forced to confront the issue. It seeks so to dramatize the issue that it can no longer be ignored." (King, 2000: 77)

\section{INTRODUCTION:}

This paper considers ways of understanding a type of thing, which is clearly a design because it works, but does not develop through the activities of professional designers. It considers theory from archaeology and design to discuss the 'lock-on' that is used in non violent direct action. It considers how such an object might have come into existence and discusses its use by peace activists in the UK, especially those who protest against nuclear weapons at Faslane, Scotland, where Britain's armed forces keep the UK's nuclear bombs. The paper intends only to open a discussion, not to present definitive conclusions about this object, or what understanding it might tell us about either design theory or archaeology. The paper briefly describes the history and current use of the lock-on, introduces some theoretical approaches that might be helpful in understanding it, and notes their possible consequences. While this discussion may be interesting in the context of theories of human/ object relationships, the facts that motivate those who over the decades have contributed to the design of the lock-on are compelling in themselves.

Britain currently has four nuclear missile submarines and up to 165 warheads. Each warhead has the destructive power of up to seven of the bombs that destroyed Hiroshima in 1945; therefore Britain has at its disposal one thousand one hundred and fifty times the destructive power of that bomb, which, along with the one dropped on Nagasaki, killed three hundred and fifty thousand people, the great majority of whom were civilians. The international court of justice ruled in 1996 that the threat to use nuclear weapons would be illegal under international law. It is facts such as these which motivate peace protest and therefore the design of lock-ons. For peace activists 'locking on' means using their bodies, and some everyday hardware, to disrupt the normal running of part of the military machine with the objective of making nuclear weapons and other weapons of mass destruction an 'issue that can no longer be ignored' as Martin Luther King put it. Locking on has a relatively long history. From the late nineteenth century suffragettes chained themselves to railings in public places as they campaigned for equal democratic rights with men. Campaigners have chained themselves to a bewildering variety of inanimate objects as part of different protest campaigns since then. Among the most notable of these in the UK have been campaigns by environmentalists against road developments.

This paper mainly refers to one of the variety of configurations of materials used by peace campaigners to lock themselves onto things and each other. It consists of a piece of $150 \mathrm{~mm}$ diameter plastic pipe a bit shorter than two human arms, a piece of nylon webbing or climbing rope and a karabiner - a quick release hook used by climbers - as well as the bodies of two participants. To lock themselves together, each protestor puts one arm into the tube, joining themselves together by the wrist using the rope and carabiner. The police can not get to their hands to separate them without cutting the pipe, but they can release themselves if they wish. Despite its having human components when in use, and only coming into existence when it is used, campaigners do refer to this configuration of pipe, webbing and carabiner as $\boldsymbol{a}$ lock-on. In direct actions the lock-on makes passive resistance to being moved out of the way more effective, since protestors are joined together in groups. The security forces can separate them against their will but only by cutting through the thick plastic of the pipe to get at the karabiner. They use saws to do this and presumably for this reason the tube is sometims covered with wire netting and then industrial tape to keep its construction concealed and increase the time it takes to forcibly unlock the participants. 
As well as being the product of a non-professional design process, the lock-on might seem like an unusual sort of object to consider in the academic study of design because it is not a discrete object but is made up of people's bodies along with its inanimate components. To exist it requires the presence of the bodies of the peace campaigners who use it to 'blockade' a military site. The lock-on clearly is 'a design', however, it does not seem to have been 'designed' in the sense the term is understood in manufacturing or the design profession; it seems to have grown up as part of the practice of non violent direct action. To this extent it can be thought of as 'indigenous' because it is a design that belongs to and has grown out of the groups that use it.

Design theory can provide some insights into the way the lock-on design may have come about. It may have some things in common with what Christopher Alexander (1964) calls a 'traditional' as opposed to a 'modern' design process, in which objects change and develop through small improvements that progressively make them a better fit with the 'problem field' that brings them into existence. In this case, the problem field consists of finding a configuration for the lock-on that will be easy to put on, will be easy to get off should the need arise, will baffle the police as to its construction for as long as possible, will be difficult and time consuming to break into, will be portable and will be cheap. Finally, and in this characteristic the lock-on conforms quite closely to Alexander's 'traditional' type of design, its configuration needs to be able to respond over time to the setting in which it is used. Because the lock-on only comes fully into existence when it is used, this aspect of the process of its 'design' involves modifications not only to its inanimate components but also its human ones. Participants in an action design the use of the lock-on by considering how many should lock together, where they should do so, how they will use diversions and the element of surprise. A lock-on is anything but an inanimate object - it is part of a process of use, which is in turn part of a wider practice. Because of this, the lock-on has come to exist through a process and is therefore also not 'modern' in another sense that Alexander's analysis proposes in that it is not individualistic but is a configuration that has grown out of various types of collective political activism. ${ }^{1}$

Having identified a relationship between the lock-on and design theory (Alexander 1964), the discussion that follows considers what sort of 'thing' a lock-on might be and what frameworks exist that might help to understand it. It refers to a further theoretical strand in Design to consider the 'performative' nature of the lock-on (Pine and Gilmour 1999) and to determine whether the lock on can be said to have evolved (Langrish 2004). The discussion then considers whether work in Archaeology may help to understand the relationship between the lock-on and its 'designers', identifying approaches that seek to understand artefacts as part of specific cultural practices (Conkey 1990). The discussion then focuses on work in Sociology that takes cultural practices to be the 'site of the social' (Reckwitz 2002) and which acknowledges the significance of objects in such practices (Kopytoff 1986, Shove 1995 \& 2005). This discussion intends to point up principles which may be applied to designs that work as part of other practices and which might facilitate changes in those practices and to identify further work on the lock-on, and other similar artefacts that might clarify these principles.

\section{WAYS OF UNDERSTANDING THE LOCK-ON AS A DESIGN}

First it is appropriate to identify the processes and agents through which this object has changed by briefly considering how the lock-on has come to its present form in the practice of non violent direct action. A complete understanding of the development of lock-on devices since the early C20 would require ethnographic and historical work which is beyond the scope of this paper. Also, given the close relationship between the specific design of a 
lock-on device and the time and place it is to be used, such an enquiry might not uncover a progressive 'development' of the form. However, we can get some useful insights into how lock-ons work by noting their variety and their relationship to the groups of people that produce them.

Central to these insights is the fact that a lock-on does not exist as a discrete object but is a manifestation of the process of non violent direct action, a 'locking-on' rather than a 'lock-on'. It is a verb rather than a noun. This observation could imply a relationship to the recent business theories that emphasise dematerialised services, sold as 'experiences' (Pine and Gilmour 1999). However, the fact that the lock-on is not provided in the usual commercial sense makes it a different case from those personalised experiences which are apparently the basis of contemporary service-based economies.

To the extent that it is an object, a lock-on device has more in common with things we might make ourselves to wear than objects with which we have a more distanced physical relationship and which we buy already made. Like clothes, the ways in which lock-ons are worn, their design in use, seem to have both practical and symbolic aspects. These two aspects can also coexist in the way that a lock-on device is made to look, as one of the keys to a successful locking-on is to deceive the police into ignoring the lock-on device until it is too late for them to stop it being used. One tactic is to disguise the lock-on tubes as something else. At its most creative, such disguise can involve transforming an apparently innocent object into a lock-on - wheelchairs and Zimmer frames are useful for this (Rundberg, 2006: 4).

Other aspects of the appearance of lock-on devices are more conventionally symbolic, such as painting the tubes with the checker pattern that is part of our collective image of a nuclear missile, or a policeman's hat. ${ }^{2}$ The idea that these lock-on devices have developed in some sense over time is attractive even if it may only be possible in principle to clearly understand quite short periods in their development. Langrish's review of the principles of biological evolution identifies which of them might be applied to design and helps to work out the extent to which evolutionary ideas may be applied to the practice of locking-on and lock-on devices. Langrish rejects Lamarckian evolution as an explanation for changes in designs on the basis that this explanation constructs design as a process of striving for success in a future that can't be known. He uses the unintended consequences of designs as the basis for his transfer of Darwinian selection to the world of artefacts - it is the unintended consequences of today's designs that give us ideas for tomorrow's designs. As he stresses, it is not designed objects that evolve - like any organism, a particular design has to live out its life with the specification it was 'born' with, more or less. To the extent that designs can be said to evolve, this process takes place at a level that is equivalent to the genetic code that defines organisms. A particular object may be modified, but this does not usually constitute a revision to its design. Borrowing from Dawkins, Langrish identifies designs as equivalent to 'memes' - culturally reproduced codes. This offers a neo-Darwinian view of design change as 'natural selection plus memes, their competition, their modes of transfer, and their transformation' (Langrish 2004: 12).

Langrish suggests that there are three types of design memes, 'selectemes' that are ideas about what to make, 'explanemes' that are ideas about why these are the right things to make and 'recipemes' that are ideas about how to make things. The lock-on as a process/ object involves all these types of ideas and they are mutually inter-dependent, indeed it may be rather difficult to distinguish between these types of idea in the whole phenomenon of locking-on as part of non violent direct action. Ideas about 'what to make', or selectemes, interact deeply with ideas about how to make things, or recipemes, in the context of particular actions. Indeed, given the nature of the lock on as an entity that only exists once enacted it is not clear whether 'what to make' in this case indicates a thing or a political intervention. Also the scale of this 'making' is not easy to pin down, since it can be taken to indicate both 
making a specific arrangement of materials outside a particular nuclear site as well as making an increase in consciousness at a national, or international, level. The same 'explaneme' is likely to be invoked by a protester talking to a policeman who tries to separate them from some piece of hardware they have locked on to as is used in public debate - that nuclear weapons are illegal under international law.

Clearly memes, which in Langrish's evolutionary view are the 'replicators', or patterns that cause designs to persist, exist in both professional design and in non professional contexts that produce designs such as non violent direct action. So to observe that lock-ons have evolved is not to differentiate them in principle from mainstream design. Also, Langrish does not restrict 'replicators' in this case to mean the patterns of ideas an individual alone can work with, which allows such ideas to be distributed in documents, representations and objects - it is not possible for an individual to hold all the details of even a simple design in their head. Just like a conventional design, the 'pattern' of a lock-on is transmitted through formal means such as training workshops as well as through text (Faslane365, 2006, and see figure 1.). However, Michael Polanyi (1966) argued that a good proportion of the knowledge we operate with as designers and in everyday life is 'tacit', and is enacted in our embodied relationship with the world. In this case of the lock-on this tacit, embodied, knowledge is diffused among the groups of activists who employ it as a tactic for direct action and it is enacted most powerfully through participating in actions.

These facts indicate that the designing of the lock on device has taken place within the processes of doing non violent direct actions, in their planning and execution and their evolution. Just as a design once produced can be modified only up to a point before it must be re-designed, a locking on action that is planned - designed - and then enacted can only be modified up to a point in the face of the police tactics that the participants find confronting them. Although peace activists prepare for and plan actions meticulously, they are necessarily working with an unknown future, as Langrish observes is the case in conventional designing. They cannot be sure their plan will be feasible or predict the reaction of the security forces to their action. Some modification of a plan is possible on the day, but the collective nature of non violent protest means that what is learned from a particular action can be effectively shared and fed into the design of future actions, and future lock ons.

This sharing of experience will affect the details of future actions, but it takes place against a background of collective knowledge and values that probably change more slowly. Because the relationship of the lock on to these other factors that make up the phenomenon of peace activism is based on a tacit understanding of how peace activism works, it may have some similarity to other forms of shared behaviour that have both material and cultural aspects. The tactic of locking on, and the knowledge that exists about why and how to do it, and what devices are good for it, are part of the cultural, material and embodied practice of non violent direct action. They are among the characteristics of what Bourdieu (1984) calls the habitus of the people who make up this group. To some extent these aspects of non violent direct action go without saying for peace activists. The lock-on is an enacted principle which is available to individuals by virtue of their belonging to the group. They become skilled in its use by absorbing the mores and values of the group as well as through explicit learning.

\section{'SOCIAL PRACTICE’ AS A THEORETICAL APPROACH TO THE LOCK ON.}

This close relationship between the process of locking-on and the way that non violent direct action works as a group phenomenon seems to be fundamental to the character of the lock-on as an artefact. This is what makes it somewhat unfamiliar, different in both its 
form and the process of its development from the type of object that designers, design theorists and design academics are usually concerned with.

Although other objects, such as spectacles and automobiles, function as lock-ons do only with the addition of a human body, artefacts like these also have a discrete character separate from the human bodies that 'activate' them. Part of the value of spectacles and cars depends on their symbolic 'content' - they are more or less fashionable for example and are so whether or not they are being worn or being driven. This seems not to be the case with lock-ons, since they fully exist only for the action for which they have been designed and in combination with the activists' bodies.

This fact alone may not constitute a significant difference between the lock-on and more conventional artefacts - indeed it is possible to think of other artefacts whose form develops as part of a collective enterprise. It is now conventional for new product development to at least take account of the characteristics of the intended market for a product, if not to base the development process on the emergent characteristics of that market captured by research techniques borrowed from anthropology (see Holbrook 1996, Waymire and Hall 1995: 41). In a parallel development, theoretical approaches to the design of computer technology have taken a 'turn to practice' which acknowledges the situated nature of experiences with technology (McCarthy and Wright 2004). However, the 'indigenous' nature of the lock-on and the fundamental interweaving of the development of the device and the nature of the groups that have developed it make it different from even such apparently market/ user orientated commercial products, though whether this makes the process of its origination fundamentally different from conventional design processes is at this point an open question.

Archaeologists have been aware of the intimate relationship between designs and the cultures that give rise to them, especially so since they began questioning what Conkey calls the 'culture history' approach to understanding artefacts. Whereas hitherto archaeologists had acted as if objects could 'stand in' for a culture, from the 1960s they aspired to unpick the multi-determined nature of artefacts and their complex mutually determining relationship to their setting. As Conkey puts it:

Design is much more than that which is applied to a pot; it is the most essential set of processes that bring form into existence. All artifacts and all cultural production are the result of a series of - or a 'pathway' through - mental and manual processes set in and defined by a historical and social framework. (Conkey 1990: 13)

It is notable for this discussion that her perspective starts from the premise that 'design' means what identifies a type of artefact and allows it to be positioned in a typology by virtue of its formal relationship to the design of other artefacts, rather than meaning a professional, commercial process that results in artefacts, though it allows for both meanings. She acknowledges that it is practices - 'mental and manual processes set in and defined by a historical and social framework' - that result in objects with particular form and refers to the notion of 'praxis' found in Marx and Bourdieu. She suggests that we can only understand objects if we think of them 'as praxis, as productions, as symbolic acts in their own right'. This thought is echoed in more recent work on consumption in sociology and anthropology, for example Miller's counterpoising of a theoretical/ semiotic approach to the analysis of consumption with an empirical/ ethnographic approach $(1995,1997)$. Seen in this way, production for Conkey is a 'constitutive endeavour'. The production of the lock-on is part of a collective endeavour that shifts and changes through time and space and constitutes the practice of non violent direct action as well as being constituted by it.

Considered in this way, the somewhat unfamiliar, perhaps bizarre, character of the lock-on may help to shed light on the way that more 'mainstream' artefacts come into being 
and how they might change to further aims besides the creation of profit. If the fact that the lock-on changes as a consequence of changes in the practice of peace activism is accepted as a principle for artefact change more generally and in more 'mainstream' settings, then changes to other types of object are likely to rely on changes to practices. This point has not been lost on those interested in working out how to modify practices that are arguably unsustainable in environmental terms. Sociologist Elizabeth Shove, for instance, has studied the way that everyday practices such as laundry, bathing and the heating and cooling of houses have grown up and the elements that keep them in existence in their current form in the developed world (2005).

Drawing from sociological and anthropological studies of technology Shove inspects the premise that societies and technologies 'co-evolve' - citing Kopytoff's assertion that societies 'simultaneously and in the same way construct objects as they construct people' (Kopytoff 1986: 90). She suggests that there are three dimensions to the co-evolution of people and technologies made up of relationships between 'sociotechnical systems' that are 'collective conventions and arrangements', the 'habits, practices and expectations of users and consumers' and the 'symbolic and material qualities of sociotechnical devices/ objects' (Shove 1995: 48). This allows her to consider the material and the symbolic aspects of technologies as well as the ways in which they 'stabilise' as large scale structures and are appropriated at a local level. So in her analysis of bathing she is able to make a relationship between the domestic technical arrangements we live with every day, the infrastructure that provides us with the means to make these arrangements work and, crucially, the very powerful sets of ideas that motivate us to clean ourselves in the particular ways that we do. What is notable in her account is the coherence with which she integrates these elements of bathing and traces the ways in which they change over time.

Shove's account has in this respect a good deal in common with the much more abstract body of theory that can be found in contemporary sociology that engages with 'social practices'. Andreas Reckwitz writes an overview of this 'practice theory' in sociology (Reckwitz 2002). He suggests that this way of thinking about the social offers an alternative view of human actions to that offered by other strands of thought. In his view, culture is the 'site of the social' and he distinguishes practice theory from theories of culture that emphasise mind, discourse and interaction (2002: 241). Reckwitz sums up a 'practice' as

\footnotetext{
'A routinised type of behaviour which consists of several elements, interconnected to one another: forms of bodily activities, forms of mental activities, 'things' and their use, a background knowledge in the form of understanding, know-how, states of emotion and motivational knowledge.' (Reckwitz 2002: 251)
}

It is characteristic of practices that these elements are interconnected and 'carried' by individuals, in whom many different practices intersect. They are sustained, not by norms or rational choices, but by routines - habits as it were - which are embodied routines that draw on 'knowledge' that can be either explicit or based in emotion. They change through 'ruptures' in the routines that sustain them.

Despite its theoretical abstraction, Reckwitz' account of practice theory points towards some quite down to earth aspects of humans' relationships to the material world. In a parallel to the principle that mind and body can't be distinguished in a practice, in this view human interactions with particular physical things are built into the meaning of practices. Echoing writers in the sociology of technology tradition such as Latour (1992, 2000), Reckwitz proposes that things 'mould' activities. Things '...enable and limit certain bodily and mental activities, certain knowledge and understanding as elements of practices' (2002: 253). In contrast to views of human object relationships that stress their discursive and symbolic content, in this view the materiality of objects, how they 'handle', constitutes the 'forms of behaviour' of which they are part. 
Practices depend on knowledge and motivations - we have to know what to do and we have to want to do it. This knowledge includes but surpasses explicit 'knowing that' and includes 'aesthetic' knowledge, feeling, emotion. Knowledge held in our feelings lets us know what to do in a situation or with a thing. ${ }^{3}$ Knowledge in a practice '...embraces ways of understanding, knowing how, ways of wanting and of feeling that are linked to each other within practice (Reckwitz 2002: 253).' This compound of different forms of knowledge includes an understanding of the values that may motivate the practice as well as how to act in accordance with them that is made evident through feelings, a certain 'emotionality'. Emotions are therefore practice-specific; they define, and reproduce the practice.

\section{AN ARTEFACT IN THE PRACTICE OF NON VIOLENT DIRECT ACTION}

The development of lock-on devices and of the ways they are used in non violent direct action set out above seems to fit rather well with the features of social practices that Reckwitz identifies. It is reasonable to class non violent direct action in peace activism as a 'practice' in this sense; ${ }^{4}$ it is collective; it operates according to shared routines; it involves specific (disobedient) bodily activities; it is motivated by knowledge of the illegality of 'our' weapons of mass destruction; this knowledge is felt as a passionate desire for action; it is based on an understanding that collective political protest can effect change. Most relevant for this discussion however, non violent direct action involves the development and use of particular artefacts - for locking on.

The lock-on in non violent direct action is a perfect example of an artefact that is part of a practice. The physical transgression of accepted behaviour that locking on requires draws on a tradition of dissent that has deep roots in British political and cultural life; a long established practice. Locking on is very obviously embodied and the way the lock-on device 'handles' both in its materiality and in the discourse of power and resistance that it 'speaks' is crucial to the practice itself. The routines of non violent direct action change in response to 'ruptures' provided by the security forces that result in changes to many elements of the practice - changes to the lock-on devices themselves being only the most visible of these. The tactics in which lock-ons are employed change in response to modifications in the knowledge that is brought to the practice.

The lock-on device could be almost too perfect an example of an artefact that is part of a cultural practice. It would be possible to dismiss practice theory as a useful starting point for thinking about designs on the grounds that while the lock-on fits the theory very closely it only does so because it is a pathological rather than normative design in social terms. Such a criticism might point to the usefulness of an approach to designs that stresses their symbolic character, appealing to the well developed body of theory that stresses the symbolic aspect of our relationship to artefacts in consumption (Baudrillard 1993) and design (Krippendorff 2005). ${ }^{5}$

Such a criticism might derive from a political judgement that rests on a view of the proper 'ends' for designing and different political positions will result in different evaluations of this point. It might also relate to the question of the appropriate definition of 'design theory, since, if Alexander's definition of 'modern' design is the only one considered acceptable it would be possible to argue that the lock-on has not properly been designed at all. If the only proper ends for designing are the creation of profit, then yes, the pathological character of the lock-on makes it an unfit model. If design is understood to be an activity circumscribed by its professional definition then the lock-on is a similarly unfit example. 
However, it is possible to see in Shove's analysis of practices on the level of interlocking social, cultural and material systems an urgent purpose for alternative ways of understanding designs and designing, similar to those adopted in the 'participative' design tradition (Ehn and Kyng 1991), but with the more radical purpose of exploring the potential to use this understanding to modify practices in the service of, for instance, environmental sustainability. The 'practice oriented' approach outlined above in relation to the lock-on has the potential to provide sufficient understanding of these systems to allow them to be changed by policy, and by practice oriented designing. Understanding material things requires understanding practices. Given that practices and things are mutually constitutive, changing things might accompany changing practices.

The discussion above implies further work that would make it possible to more confidently specify the insights the lock-on, and other indigenous designs, can provide. A more complete historical/ ethnographic study of the way the design has come about, and how it changes, would be a very significant element in this work. This would make it possible, for instance, to ascertain whether the group organisation involved in non-violent direct action and the development of lock-ons was equivalent to, or significantly different from, the organisation of the participative and community based design traditions that appear to be its closest relations. With an opposite disciplinary orientation, such a study would also make it possible to determine the significance of the lock-on for sociological theories of human/ object relationships.

\section{Acknowledgement}

This paper has been strongly influenced by my participation with Sabine Hielscher in the 'Designing and Consuming' workshops organised in 2005/ 2006 by Elizabeth Shove, Matt Watson and Jack Ingram. It would also not have been written without Jill Gibbon's and Rosa Fisher's courageous participation in Faslane365 and their kind advice on writing the paper.

\section{Figures}
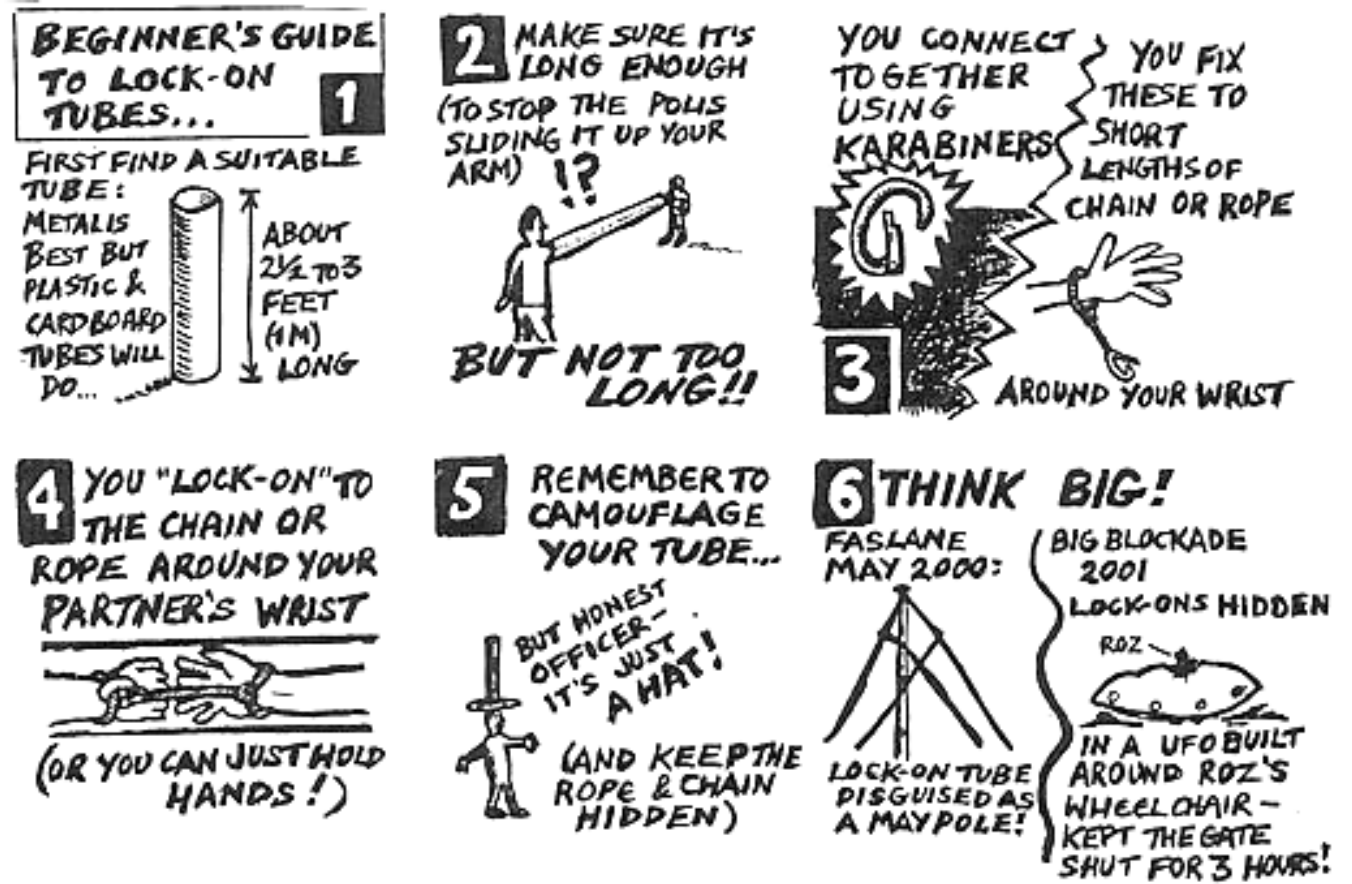

Figure 1. Lock on training material 


\section{Footnotes}

Alexander, C. 1964 Notes on The Synthesis Of Form, Harvard University Press Baudrillard, J. 1993 Symbolic Exchange and Death, London: Sage

Bourdieu, P 1977 Outline of a Theory of Practice, Cambridge University Press

Bourdieu, P 1984 Distinction: A Social Critique Of The Judgement Of Taste, London:

Routledge

Buchanan, R 2001 'Human Dignity and Human Rights: Thoughts on the Principles’ Design Issues, 17, 3: 35-50

Conkey, M And Christine A. Hastorf 1990 The Uses of Style in Archeology, Cambridge:

Cambridge University Press

Cross 2006 'Forty years of design research' Design Research Quarterly, 1, 2: 3-5

Ehn, P and Kyng, M 1991 : 'Cardboard Computers'. In: Greenbaum, Joan,

Kyng, Morten (Eds.) Design At Work: Cooperative Design Of Computer Systems. Lawrence

Erlbaum Associates

Faslane365 Blockading Tactics, at: http://www.faslane365.org/en/blockading_tactics,

Accessed 10.12.2006

Holbrook, M. 1996 'Romanticism, introspection and the roots of experiential consumption: morris the epicurean', in Belk R., Venkatesh, A, \& Dholakia, N. (eds) Consumption and Marketing: Macro Dimensions, Cincinatti: South Western College Pulbishing

King, Martin Luther 2000 Why We Can't Wait, Signet Classics

Krippendorff, Klaus 2005 The Semantic Turn: A New Foundation For Design, London:

Routledge

Langrish, J. Z. 2004 'Darwinian Design: the memetic evolution of design ideas', Design

Issues, 20, 4: 4-19

Langrish, J. Z 1999 ' Different Types of Memes: Recipemes, Selectemes and Explanemes.'

Journal of Memetics, 3, 2: 109-122

Latour, B. 1992 'Where are the missing masses? the sociology of a few mundane artifacts', in

Weibe Bijker and John Law (eds), Shaping Technology/ Building Society: Studies in

Sociotechnical Change, 225-258, Massachusetts, MIT Press

Latour, B. 2000 'The Berlin key, or how to do words with things', in P. M. Graves-Brown

(ed), Matter, Materiality and Modern Culture, London: Routledge

Mccarthy, J \& Peter Wright 2004 Technology as Experience, Massachusetts: The MIT Press

Miller, D. 1995 'Consumption and Commodities', Annual Review of Anthropology, Vol 24

P141-161

Miller, D. 1997 'Could shopping ever really matter’, The Shopping Experience, London: Sage (Theory Culture and Society

Polanyi, M 1966 The Tacit Dimension, Massachusetts: Doubleday and Company

Rundberg, A-L 2006 '64 down, 301 to go' Peace News, 2480-2481 December 2006 -

January 2007: 4

Reckwitz, A 2002 'Towards a theory of Social Practices: a development in culturalist

theorizing' European Journal of Social Theory, 5, 2: 243-263

Schiffer, M B 1999 The Material Life of Human Beings: Artifacts, Behavior and

Communication, London: Routledge

Shove, E. 2005 Comfort, Cleanliness and Convenience: the Social Organization of

Normality, Oxford: Berg

Shove, E. 2006 A manifesto for practice oriented product design, Designing and Consuming workshop, Durham University

Waymire, G, M. Barry, \& R.C. Hall, 1995 'Materializing Culture’, Design Management

Journal, Spring, p40-45 
1 Although Alexander offers a stereotype of the modern designer as someone who works alone, contemporary design processes do not necessarily conform to this individualistic pattern. However some of the characteristics of Alexander's 'modern' design process are found in the commercial production of contemporary artefacts. These are often individualised through a brand, and sometimes through the identity of a named designer, for all that there are now conventionally many players in any process of new product development including teams of designers.

2 Although lock-ons do have symbolic content, the fact that its purpose is to confuse the opposition, rather than to maximise their ease of their use puts them in a particular relationship to the application of theories of language to design found, for instance, in the writing of Klaus Krippendorff (2005). The exact nature of this relationship warrants further research, particularly the way in which their symbolic content is subversive not normative.

${ }^{3}$ In this sense, social practices have something in common with the memes that Langrish discusses they are patterns that guide our actions, which replicate and aspects of which may mutate. As Langrish points out however (1999), the transmission of memes through time is not restricted to cultural means. 4 One feature of practice theory that is not immediately clear is the grounds for naming a particular activity as a practice, rather than its components, or activities of which it is a part. It seems reasonable to assume that sociologists would base this classification on the activity having social significance being a genuine 'site of the social'. However it is not clear how this criterion should be used empirically. Given that different interests are at stake in Design than in Sociology it is also reasonable to assume that different classification criteria for practices might validly be used in the two disciplines. 5 Archaeology provides other ways of conceiving of the meaning of objects, for instance Schiffer's (1999) account of the communicative potential of artefacts. 